\title{
PERCEPTION OF FACULTY ON VERTICAL INTEGRATION- AS A TEACHING LEARNING METHOD IN UNDERGRADUATE MEDICAL EDUCATION
}

\author{
Madhusmita Panda1, Mohua Biswas ${ }^{2}$
}

${ }^{1}$ Associate Professor, Department of Anatomy, SCB Medical College, Cuttack, Odisha, India.

${ }^{2}$ Associate Professor, Department of Community Medicine, SCB Medical College, Cuttack, Odisha, India.

ABSTRACT
BACKGROUND
Integrated teaching, an important educational strategy, is the need of the hour. It has to be an imp
curriculum. This study was carried out with the following objectives-
1. To compare the perception of preclinical, paraclinical and clinical faculty on vertical integration.
2. To determine the faculty perception on effectiveness of vertical integration.
3. To determine the difficulties in execution of vertical integration.

\author{
METHODS \\ Study Design- Cross sectional observational study. \\ Place of Study- SCB Medical College and Hospital, Cuttack, Odisha. \\ Study Period- Oct 2017 to Dec 2017. \\ Study Subjects- 20 preclinical, 36 para-clinical and 63 clinical, teaching faculties. \\ Study Sampling- $50 \%$ of faculties willing to participate were selected by simple random sampling. \\ Study Instrument- Pre-designed \& pre-tested self-administered questionnaires.
}

\section{RESULTS}

Out of 20, $36 \& 63$ faculties, $55 \%$ pre-clinical and 55.55\% para-clinical and $77.42 \%$ clinical faculties agreed to go for integrated teaching. $67.74 \%$ clinical faculties felt that there was unnecessary repetition of the chapters in the present scenario. 8.06\% clinical faculties perceived that students are confused without clinical correlation. 90.67\% preclinical, $61 \%$ para-clinical and $87.10 \%$ clinical faculties perceived that it is difficult for the students to understand and gain mastery over the subject without clinical correlation. 60.99\% preclinical, 66.67 para-clinical and. $67.74 \%$ clinical faculties felt that students find it difficult to connect themselves with topics of different disciplines when they are taught at different times without any integration. $90.01 \%$ preclinical, 88.89\% para-clinical and $95.16 \%$ clinical faculties have agreed that problem based learning will be the chief motto of vertical integration. 90\% preclinical, $88.89 \%$ paraclinical and $87.10 \%$ clinical faculties agreed that learning will become more interesting if integrated teaching is followed. That improvement in cognitive and psychomotor domains will be achieved in vertical integration was noted by $60.43 \%, 83.33 \%$ and $83.87 \%$ of the pre, para and clinical faculties. $85.23 \%$ preclinical, $88.89 \%$ para clinical and $74.19 \%$ clinical faculty agreed to the fact that integrated teaching will facilitate better interdisciplinary coordination. $92.76 \%$ clinical, $79.45 \%$ para-clinical, and $84.32 \%$ pre-clinical faculties agreed that integration would help in appreciation and application of the basic science knowledge to different diseases.

\section{CONCLUSIONS}

Most of the faculties perceived that vertical integration would facilitate learning. Most of the faculties opined that integration from entry level to completion, will improve understanding.

HOW TO CITE THIS ARTICLE: Panda M, Biswas M. Perception of faculty on vertical integration- as a teaching learning method in undergraduate medical education. J. Evolution Med. Dent. Sci. 2019;8(14):1120-1123, DOI: 10.14260/jemds/2019/248

\section{BACKGROUND \\ Integration is defined as a well-structured organization of teaching matter to interrelate and simultaneously unify the subjects which are frequently taught in separate academic courses and departments. Literarily integration means "to make entire".[1]}

'Financial or Other Competing Interest': None.

Submission 30-01-2019, Peer Review 22-03-2019,

Acceptance 28-03-2019, Published 08-04-2019.

Corresponding Author:

Dr. Mohua Biswas,

Department of Community Medicine,

SCB Medical College,

Cuttack-753001,

Odisha, India.

E-mail: drmohuabiswas@yahoo.com

DOI: $10.14260 /$ jemds $/ 2019 / 248$

\section{(c) (i) $(-$}

It is a fact that every medical graduate has to be a lifelong learner, and this is possible only when learning, observing and performing is a continuous process. Howsoever in medical curriculum, learning is enhanced only when the students are actively engaged in topics which are interrelated with each other meaningfully.[1,2] This is much better achieved only when the subjects are aligned for integration both horizontally and vertically.

As the name implies 'integration' involves several subjects, where importance of individual subjects is subordinated to the main goal of training a functional physician. ${ }^{[3]}$

Indian medical colleges are still following the fragmented discipline-based type of curriculum which is having the basic or the preclinical subjects in the initial years, then paraclinical and finally the clinical subjects which are taught in separate semesters. Repetition, overlapping and redundancy are the ongoing factors which are hammering almost every institutional educational process. There are some kind of 
restrictions and backpressures in the advancements of the qualitative and quantitative achievements in the field of health care which has instigated the Medical Council of India to suggest for the Curriculum Based Medical Education or problem based learning for the undergraduates.[1, 2] Since integrated teaching an important educational strategy is the need of the hour, it has to be an important aspect of the modified curriculum. In this scenario certain topics which are common to certain subjects can be taught on a common platform thus bringing forward the integrated teaching to the forerun.

When the resistance to antibiotics and other drugs is increasing day by day, so also there is a rapid change in the disease processes as well as their manifestations and thus the medical fraternity is also thinking for a change in the teaching learning processes in order to produce a very capable Indian Medical Graduate who can cope up to all these advancements. Keeping this in view this study was carried out to know the perception of the faculty of different disciplines about integrated teaching in medical science.

\section{Objectives of The Study}

1. To compare the perception of preclinical, paraclinical and clinical faculty on vertical integration as a teaching learning tool in undergraduate education.

2. To determine the faculty perception on effectiveness of vertical integration on student learning.

3. To determine the difficulties in execution of vertical integration in undergraduate curriculum.

\section{METHODS}

\section{Study Design}

Cross Sectional Observational study.

\section{Place of Study}

SCB Medical College and Hospital, Cuttack, Odisha.

\section{Study Period}

Oct 2017 to Dec 2017.

\section{Study Subject}

20 members of the preclinical departments, 36 from the paraclinical and 63 from the clinical disciplines were taken for our study.

\section{Study Sampling}

Out of all the faculties present in preclinical, para-clinical and clinical disciplines, willing to participate in the study and present at the time of data collection $50 \%$ of them were selected by simple random sampling.

\section{Study Instrument}

Pre-designed \& pre-Tested Self-administered Questionnaires validated by the resource persons of the MCI Regional Training Centre of SCB Medical College, Cuttack.

After the study was approved by the Institutional Ethics Committee of SCB Medical College informed consent was obtained from the respective faculties of pre, para and clinical departments of SCB Medical College and then data was collected using self-administered Questionnaires. The data thus collected was statistically analysed.

\section{RESULTS}

Out of 20, 36\&63 faculties Pre-clinical, Para-clinical and clinical department $55 \%$ of the pre and $55.55 \%$ para- clinical and $77.42 \%$ of the clinical faculty agreed to go for integrated teaching, In a similar study conducted by Seema Kumar et.al $89 \%$ faculty felt integrated teaching leads to better learning and clinical co-relation among students and 79\% think it would be more helpful to them in their clinical practice.[4]

Most of clinical faculty i.e., $67.74 \%$ felt that there was unnecessary repetition of the chapters in the present scenario of teaching whereas only $40 \%$ of pre-clinical and $44 \%$ of papa -Clinical.

There is disjointed approach to teaching was felt by 74.19 $\%$ of the clinical, $50.00 \%$ of the para-clinical \& $50.15 \%$ preclinical faculties.

Maximum number of the clinical faculty have perceived that there was frequent repetition of the basic science chapters as the students went up the step ladder pattern of the teaching schedules in the different years As a result of this repetition and the disjointed approach there is unnecessary wastage of time while giving a touch up to the basic science part of each clinical topic in the clinical years and so also, the students gradually lose interest when the teacher actually comes to the clinical part of the topic within the one hour lecture.

\begin{tabular}{|c|c|c|c|c|}
\hline $\begin{array}{l}\text { Sl. } \\
\text { No. }\end{array}$ & Questions of the Questionnaire & $\begin{array}{l}\text { Pre-Clinical } \\
\mathrm{N}=\mathbf{2 0}\end{array}$ & $\begin{array}{l}\text { Para-Clinical } \\
\mathrm{N}=36\end{array}$ & $\begin{array}{c}\text { Clinical } \\
\mathrm{N}=63\end{array}$ \\
\hline 1 & Should we go for integrated teaching or not? & $55 \%$ & $55.55 \%$ & $77.42 \%$ \\
\hline 2 & There is unnecessary repetition of the subject & $40.23 \%$ & $44.44 \%$ & $67.74 \%$ \\
\hline 3 & Disjointed approach to teaching & $50.15 \%$ & $50 \%$ & $74.19 \%$ \\
\hline 4 & Confusion in students mind due to difference in opinion & $25.65 \%$ & $27.78 \%$ & $58.06 \%$ \\
\hline 5 & Students cannot grasp the subject as a whole without clinical correlation & $90.67 \%$ & $61 \%$ & $87.10 \%$ \\
\hline 6 & Students find it difficult to connect with the same topics of different disciplines & $60.99 \%$ & $66.67 \%$ & $67.74 \%$ \\
\hline 1 & It will deal with problem-based learning & $90.01 \%$ & $88.89 \%$ & $95.16 \%$ \\
\hline 2 & Improve understanding of the subject due to continuous teaching. & $85.22 \%$ & $86.11 \%$ & $80.64 \%$ \\
\hline 3 & Learning will become more interesting & $90 \%$ & $88.89 \%$ & $87.10 \%$ \\
\hline 4 & The students will have improved cognitive and psychomotor domains & $60.43 \%$ & $83.33 \%$ & $83.87 \%$ \\
\hline 5 & Help in coordination among faculties of different departments & $85.23 \%$ & $88.89 \%$ & $74.19 \%$ \\
\hline 6 & $\begin{array}{l}\text { Helps in appreciation and application of the basic science knowledge to health and } \\
\text { disease. }\end{array}$ & $84.32 \%$ & $79.45 \%$ & $92.76 \%$ \\
\hline 7 & \begin{tabular}{|c|} 
Output of a better Indian Medical Graduate \\
\end{tabular} & $90.12 \%$ & $86.11 \%$ & $83.87 \%$ \\
\hline
\end{tabular}




\section{DISCUSSION}

There is confusion in the students' mind due to differences in opinions of various faculty as the student rises from the basic sciences to the clinical sciences along the semesters. However only $25.65 \%$ of the preclinical faculty and $27.78 \%$ of the para-clinical faculty have agreed upon this concept, as in these initial years the tender minds of the students have not grasped every detail of the subjects. According to the faculty it is said that only when the students go to the clinical years then only, they can appreciate the differences of the opinions of the various teaching modules of the various teachers. So $58.06 \%$ of the clinical faculty has perceived this fact that there is some kind of confusion in the students' mind while teaching the same topic over the years.

It was observed that $90.67 \%$ of the preclinical faculty, $61 \%$ of the para-clinical and $87.10 \%$ of the clinical faculty perceived that it becomes difficult for the students to understand and gain mastery over the subject without clinical correlation when they are in the initial years of their MBBS career and similarly it is also not that easy for them to remember the chapters without correlation with the basic sciences when they are in their clinical classes.

Perception of $60.99 \%$ preclinical, 66.67 para-clinical and $67.74 \%$ clinical faculty established the fact that students find it difficult to connect themselves with the same interrelated topics of different disciplines when they are taught at different times without any integration.

Having a view of the perception of the different faculty regarding the disadvantages of the present system of teaching and learning we have made an effort to find out the advantages of integration of the vertical variety through the questionnaires given to the faculty of all the departments of this college. Thus, it was observed that $90.01 \%$ of the preclinical, $88.89 \%$ of the para-clinical and $95.16 \%$ of the clinical faculty have agreed to the fact that problem-based learning will be the chief motto of vertical integration. The students would be grilled and polished in a better way if they would be exposed to the problems from the beginning in a systematic manner. The fact that, there will be improvement in the understanding of the subject due to continuous teaching was approved by $85.22 \%, 86.11 \%$ and $80.64 \%$ of the preclinical para clinical and the clinical faculty respectively. In the Study conducted by Seema Kumar et.al. $72 \%$ of faculty agreed that Integrated teaching improved understanding and application of basic science knowledge of students. $90 \%$ of faculty felt that it will help better performance in later days of clinical training. ${ }^{[4]}$

On evaluation of the questionnaires it was observed that $90 \%$ of the preclinical, $88.89 \%$ of the paraclinical and $87.10 \%$ of the clinical faculty agreed to the fact that learning will become more interesting if integrated type of teaching is followed in the curriculum. That improvement in the cognitive and psychomotor domains of the learning process of the students will be achieved in vertical integrated learning was noted by $60.43 \%, 83.33 \%$ and $83.87 \%$ of the pre, para and clinical faculty.

It was also found that $85.23 \%$ of preclinical, $88.89 \%$ of the paraclinical and $74.19 \%$ of the clinical faculty agreed to the fact that integrated teaching will facilitate better interdisciplinary coordination among the departments. Maximum number of faculties i.e. $92.76 \%$ clinical $79.45 \%$ Para- clinical and $84.32 \%$ pre-clinical faculties agreed that integration would help in appreciation and application of the basic science knowledge to the different disease processes and thus help in production of a better Indian Medical Graduate.

Integrated teaching will help in to bring out better medical graduate were opened by $90.12 \%$ of pre-clinical, $86.11 \%$ para- clinical \& $83.87 \%$ clinical faculties. In a study conducted by Jennifer K et.al Found that Clinicians were less positive about curricular integration as compared to their basic science counterparts.[5]

In response to the open-ended questions $78 \%$ of the total faculty agreed that development of the curriculum was a herculean task and rearrangement of the classes with time factor being a hindrance was a leading problem in integrated teaching. In the study conducted by Jennifer K et.al the main obstacles cited by the faculties were lack of a reward system for faculty to put effort into integration and lack of time.[5]

But still it was observed that maximum number of the preclinical, paraclinical and clinical faculty agreed simultaneously that a better qualified Indian Medical Graduates can be produced with vertical integration.

\section{CONCLUSIONS}

As perceived by maximum number of faculty, it was found that vertical integration would facilitate the enhancement of the learning process of the learner by preferably dealing with problem-based scenarios. Simultaneously, due to the continuous teaching process going on with integration between the basic sciences and the clinical subjects, running at par with each other, integrated teaching would obviously improve the understanding of the subjects by learners. Teachers too felt that the students shall have improvement in their cognitive and psychomotor domains because of the integration process. The main drawback of the present teaching learning system is unnecessary repetition of the study matter among various disciplines on a subject along with disjointed approach which sometimes causes confusion in the students' mind. It can very well be avoided by promoting vertical integration.

Most of the faculty opined that a lot of time can be allotted to every system of the human body as the integration shall proceed from the very entry level to the completion of course of every Indian Medical Graduate. Thus, this will improve the understanding of the subject by the learners along with appreciation and application of the core basic science knowledge towards the diagnosis of all the diseases. However, most of them also told that change in curriculum and rearrangement of classes along with coordination with various departments would be the most important hurdle to bring about this change.

\section{REFERENCES}

[1] Joglekar S, Bhuiyan PS, Kishore S. Integrated teaching - our experience. J Postgrad Med 1994;40(4):231-2.

[2] Ghosh S, Pandya HV. Implementation of an integrated learning program in neuroscience during the first year of the traditional medical course: perception of the students and faculty. BMC Medical Edcation 2008;8:44.

[3] Haranath PSRK. Integrated teaching in medicine Indian scene. Indian Journal of Pharmacology 2013;45(1):1-3. 


\section{Jemds.com}

[4] Kumar S, Dohare S. Faculty perceptions regarding introduction integrated teaching in physiology. International Journal of Bio-Medical Research 2013;4(4):3682-5.

\section{Original Research Article}

[5] Brueckner JK, Gould DJ. The Health science faculty members' perceptions of curricular integration: insights and obstacles. J International Association of Medical Science Educator 2006;16:31-4. 